\title{
Juizado de Violência contra a Mulher de Ponta Grossa: contextualizando a realidade e desvelando possibilidades de atuação
}

\author{
Court violence against women tip thick: \\ contextualizing the reality and unveiling of \\ possibilities performance
}

\author{
Bruna Woinorvski de Miranda* \\ Alessandra Pimentel Munhoz do Amaral ${ }^{\star *}$ \\ Katriny Renosto Lazarin ${ }^{* *}$
}

\begin{abstract}
Resumo: Além de promover um apanhado teórico acerca da questão da violência contra a mulher, o presente artigo apresenta uma pesquisa por amostragem realizada em processos eletrônicos de Medidas Protetivas de Urgência do Juizado de Violência Doméstica e Familiar contra a Mulher da comarca de Ponta Grossa, cujos dados permitiram traçar o perfil das vítimas e dos agressores, bem como mapear as ocorrências de violência contra a mulher na cidade. Tal estudo possibilitou o reconhecimento da realidade institucional e das demandas atinentes ao Juizado, levando a reflexões que desvelam intervenções condizentes com a realidade e necessidades da população atendida.
\end{abstract}

Palavras-chave: Violência. Mulher. Vara Criminal.

\begin{abstract}
Apart from promoting a theorical summary about question of violence against women, this article presents a sample research conducted in eletronic processes of restraining urgency orders of Domestic and Family Violence against women Court of Ponta Grossa, whose data allow to profile victims and offenders, as well as mapping the occurences of violence against women in this city. Such work, hás enabled the recognition of reality institutional and demands relating to court, taking the reflexion that reveal consistence interventions with reality and the population served needs.
\end{abstract}

Keywords: Violence. Woman. Criminal Court.

Recebido em: 10/02/2015. Aceito em: 20/07/2016

\footnotetext{
"Especialista em Gestão de Organizações Públicas pela Universidade Federal do Paraná - UFPR (2011) e Especialista em Gestão Pública Municipal pela Universidade Estadual de Ponta Grossa - UEPG (2011). Pós-graduanda em Acolhimento Institucional e Familiar pela Pontifícia Universidade Católica do Paraná - PUC/PR, em Intervenção Sociocultural pela Universidade Estadual do Centro-oeste do Paraná - Unicentro e em Gestão em Saúde pela Universidade Federal do Paraná - UFPR. Graduada em Serviço Social pela Universidade Estadual de Ponta Grossa - UEPG (2009).

"Juíza de Direito Titular do Juizado de Violência Doméstica e Familiar contra a Mulher de Ponta Grossa.

"*t"Graduanda do Curso de Serviço Social da Universidade Estadual de Ponta Grossa - UEPG.
} 


\section{Introdução}

Dados de um estudo preliminar realizado pelo Ipea (Instituto de Pesquisa Econômica Aplicada) em 2013 apontam que entre os anos de 2009 e 2011 foram registrados no Brasil 16,9 mil casos de feminicídios - que se tratam de homicídios de mulheres causados por conflitos de gênero, especialmente oriundos de conflitos entre cônjuges. Segundo dados do Mapa de Violência (2012) o Brasil ocupa a sétima posição no ranking de países com maiores índices de violência contra a mulher.

Diante de inúmeros casos de violência contra mulheres fez-se necessário a promulgação de legislação específica para a sua proteção com a criação de mecanismos de coibição e punição dos agressores. Assim, depois um longo processo histórico e social, foi criada a Lei $n^{\circ} 11.340$, de 7 de agosto de 2006, popularmente conhecida como "Lei Maria da Penha", cujo objetivo principal é a erradicação de toda forma de violência contra a mulher.

A mesma legislação define a violência contra mulher como doméstica ou familiar, sendo que a primeira é compreendida como aquela que ocorre no espaço de convívio das pessoas, e a segunda vai para além deste ambiente, desde que a vítima e o agressor tenham alguma relação, seja ela de parentesco, afinidade ou civil.

A Lei Maria da Penha também dispõe sobre a criação dos Juizados de Violência Doméstica e Familiar contra a Mulher, o que também passou a ser recomendado pelo Conselho Nacional da Justiça na sequência ${ }^{1}$. Ademais, a estruturação física e humana dos referidos Juizados foi regulamentada ${ }^{2}$ visando a disponibilização de atendimentos e serviços que contemplem as necessidades das mulheres vítimas de violência.

Diante da ampliação de estruturas e em consonância a esse movimento de proteção à mulher vítima de violência é que se vislumbrou a realização de levantamento de dados junto ao Juizado de Violência Doméstica e Familiar

\footnotetext{
1 Recomendação $n^{\circ}$ 09, de 08 de março de 2007. Recomenda aos Tribunais de Justiça a criação dos Juizados de Violência Doméstica e Familiar contra a Mulher e a adoção de outras medidas.

2 Vide o Manual de rotinas e estruturação dos Juizados de Violência Doméstica e Familiar contra a Mulher do Conselho Nacional de Justiça.
}

contra a Mulher de Ponta Grossa, com o intuito de reconhecer as demandas e construir formas de intervenções condizentes com as suas necessidades. Tal levantamento decorre de uma pesquisa documental realizada pelo setor de serviço social através da análise dos processos eletrônicos de requisição de medidas protetivas de urgência em andamento no ano de 2014 na referida Vara, sendo que o reconhecimento dos marcos sociais e histórico-legais que permeiam a problemática foram base para a pesquisa.

\section{Contextualização teórica sobre a violência contra a mulher}

A questão da violência trata-se de algo que permeia nosso cotidiano e atinge todas as nacionalidades, classes e etnias. Compreendida empiricamente como uma das formas de manifestação da pobreza e da exclusão social, sua origem e consequências nem sempre se reduzem a situações simplistas e pontuais. Nesse sentido, diversas são as definições encontradas para a violência, pontuadas a partir de diferentes perspectivas. Contudo, sem cercear tais possibilidades, pode-se afirmar, resumidamente, que:

[...] A violência seria a relação social de excesso de poder que impede o reconhecimento do outro - pessoa, classe, gênero ou raça - mediante o uso da força ou da coerção, provocando algum tipo de dano, configurando o oposto das possibilidades da sociedade democrática contemporânea (TAVARES DOS SANTOS, apud PEREIRA \& PEREIRA, 2011, p. 24).

Dessa forma, a violência pode ser direcionada contra grupos específicos (em geral, vulneráveis) como idosos, índios, negros e, dentre outras possibilidades, contra mulheres.

\section{Marcos sociais, histórico-legais e aspectos conceituais a respeito da violência contra a mulher}

Dias (2010), ao realizar uma busca da trajetória histórica percorrida até o reconhecimento social da violência contra a mulher, coloca que:

Desde os tempos bíblicos que a mulher tem passado por gravíssimas violações em seus direitos mais elementares, como direito à 
vida, à liberdade e a disposição de seu corpo. [...] Há pelo menos 2500 anos, alicerçou-se a construção ideológica da superioridade do homem em detrimento da mulher, e consequentemente a sua subordinação ao mesmo (DIAS, 2010, p. 01).

As ponderações da autora nos remetem à compreensão de que a religião exerceu (e continua exercendo) grande influência na sociedade no que tange ao papel desempenhado pela mulher. Além da questão levantada, considera-se que outros valores pessoais e culturais perpassados ao longo do tempo também tenham repercutido com o passar dos anos na forma de educação dos filhos e contribuído para a perpetuação da ideologia de superioridade masculina.

Nas civilizações gregas, por exemplo, a mulher era vista como uma criatura subumana, inferior ao homem, menosprezada moral e socialmente, e não tinha direito algum; já na Alexandria romanizada, a mulher era tida como alma inferior e símbolo de menor racionalidade; semelhante ao que ocorria na Idade Média onde nada era permitido à mulher - a quem competia unicamente a função de obedecer ao marido e gerar filhos. Por fim, a reprodução de ideias parecidas pode ser notada na sociedade moderna.

Ante ao exposto, é possível afirmar que:

As diversas formas de agressão existentes têm sua gênese no cenário cultural histórico de discriminação e subordinação das mulheres. A desigualdade criada em torno do masculino e do feminino abriu as portas para uma série de comportamentos relacionados ao domínio e ao poder de homens sobre mulheres, gerando o uso da violência. O homem historicamente recebeu da sociedade o aval para ser o chefe da casa, passando a crer que possui o direito de usar a força física sobre sua companheira ou ex-companheira, como forma de impor e cobrar o comportamento que considera adequado para si e para ela (PEREIRA \& PEREIRA, 2011, p. 23).

Contudo, significativas mudanças ocorreram nesse cenário com a consolidação do sistema capitalista. Conforme aponta Pinafi $(2007$, p. 01), o modo de produção vigente: "afetou o trabalho feminino levando um grande contingente de muIheres às fábricas. A mulher sai do lócus que até então lhe era reservado e permitido - o espaço privado, e vai à esfera pública". E, quando isso ocorre, inicia-se um processo de contestação do entendimento de inferioridade do sexo feminino ante o masculino que resulta na articulação de mulheres com o intuito de apontar a possibilidade de ambos os sexos realizarem as mesmas tarefas.

Tal articulação, conhecida como movimento feminista, ao questionar a construção social da diferença dos sexos, possibilitou o início das discussões acerca do binômio dominação-exploração social e historicamente construído, na qual os homens teriam o direito de dominar e controlar suas mulheres, utilizando-se inclusive da violência, caso fosse necessário (PINAFI, 2007).

Porém, o reconhecimento da questão e a negação da violência contra a mulher por organismos internacionais demorou a ocorrer e, somente em meados da década de 1950 a Organização das Nações Unidas (ONU) criou a Comissão de Status da Mulher, formulou uma série de tratados baseados em provisões da Carta das Nações Unidas (que expressa a igualdade dos direitos entre homens e mulheres) e na Declaração Universal dos Direitos Humanos (que declara que todos os direitos e liberdades humanos devem ser aplicados igualmente a homens e mulheres, sem distinção de qualquer natureza).

Desde então, várias ações foram implantadas em todo o mundo objetivando a promoção dos direitos da mulher.

Já no cenário brasileiro, a década de 1970 apresenta-se como marco por se tratar do primeiro período em que foram identificados movimentos feministas organizados e politicamente engajados em defesa dos direitos da mulher contra o sistema social opressor - o machismo, contribuindo para a visibilidade da questão.

O movimento "SOS Mulher" (com atividades iniciadas em São Paulo e estendidas ao Rio de Janeiro e a Porto Alegre no mesmo período), por exemplo, constituiu-se como espaço de reflexão e propositura de mudanças nas condições de vida das mulheres vítimas de violência. Trata-se de uma das primeiras iniciativas de buscar parcerias com o Estado que resultassem na resolução da problemática.

Acompanhando esse movimento e, em consonância com a dinâmica internacional, em 1979, ao ratificar a Convenção para a Eliminação de Todas as Formas de Discriminação contra a Mulher constituída a partir da Assembleia Geral 
das Nações Unidas (CEDAW), o Estado brasileiro se comprometeu perante o sistema global a coibir todas as formas de violência contra a mulher e a adotar políticas destinadas a prevenir, punir e erradicar a violência de gênero.

Em 1988 pode-se destacar outro grande avanço a partir da Constituição Federal Brasileira, quando foram incorporados aos direitos e garantias do seu texto original, aqueles estabelecidos em decorrência de acordos e tratados internacionais, tais como a própria CEDAW e a resolução da Convenção de Belém do Pará (Convenção Interamericana para Prevenir, Punir e Erradicar a Violência contra a Mulher, concluída em Belém do Pará, em 9 de junho de 1994). Como expressa o artigo quinto, parágrafo segundo da referida legislação: "os direitos e garantias expressos nesta Constituição não excluem outros decorrentes do regime e dos princípios por ela adotados, ou dos tratados internacionais em que a República Federativa do Brasil seja parte" (BRASIL, 1988, p. 15-16).

Contudo, pode-se afirmar que o ápice pelo reconhecimento da questão e a luta contra a violência contra a mulher no Brasil ocorreu somente após a promulgação da Lei no 11.340/2006, popularmente conhecida como "Lei Maria da Penha", cujo objetivo principal constituiu-se em erradicar toda forma de violência contra a mulher.

A Lei que protege as mulheres contra a violência recebeu o nome de Maria da Penha em homenagem à Maria da Penha Maia Fernandes - mulher vítima de violência que buscou até os últimos recursos para evidenciar socialmente a importância de proteger as mulheres da violência sofrida no ambiente doméstico e/ou familiar.

A referida legislação trouxe alterações significativas no Código Penal Brasileiro e possibilitou que agressores de mulheres no âmbito doméstico ou familiar fossem presos em flagrante ou tivessem sua prisão preventiva decretada. A mesma lei também versa que tais agressores não poderão mais ser punidos com penas alternativas, bem como prevê medidas protetivas de urgência que vão desde a saída do agressor do domicílio e a proibição de sua aproximação da mulher agredida, tudo para que lhe seja assegurada a sua proteção.

Ademais, a Lei Maria da Penha apresenta em seu texto uma tipificação das formas de manifestação da violência, caracterizando-as como doméstica (aquela configurada no espaço de convívio permanente das pessoas, com ou sem vínculo de parentesco) ou familiar (ocorrida no espaço da família, ou seja, dentro do grupo daqueles que são ou se consideram aparentados, unidos por laços naturais, por afinidade ou por vontade expressa), bem como definindo-as:

a) violência física: qualquer ação que atinja a saúde corporal da mulher;

b) violência psicológica: caracterizada por ações destinadas a controlar as ações, comportamento ou decisões da mulher. Geralmente se manifesta na forma de ameaças, intimidações, manipulação, humilhações ou qualquer outra forma que traga prejuízos a saúde mental e emocional da mulher;

c) violência moral: voltada às práticas de caluniar, injuriar ou difamar a mulher,

d) violência patrimonial: se refere a ações que atentem contra o patrimônio da mulher, ou seja, quando o agressor toma posse ou destrói objetos pessoais da vítima (como documentos, roupas, instrumentos de trabalho ou bens); e,

e) violência sexual: entendida como ações que obrigam a mulher a participar, presenciar ou manter relações sexuais sob o uso de força física, chantagem, ameaças ou intimidações. Relaciona-se também com a ação de forçar a mulher a prática do aborto, prostituição, ou ainda, que a impeça de utilizar mecanismos contraceptivos.

Depois da Lei Maria da Penha, outros documentos foram sendo construídos com o propósito de contribuir para a visibilidade da questão da violência contra a mulher bem como prever mecanismos de prevenção da violência e de punição aos agressores no Brasil, como o Plano Nacional de Políticas para as Mulheres (que expõe o planejamento do governo federal em enfrentar as desigualdades entre mulheres e homens, reconhecendo o papel fundamental do Estado nesse processo) e o Pacto Nacional Pelo Enfrentamento à Violência contra a Mulher (que reconhece a necessidade da adoção de Políticas Públicas, de caráter universal, acessíveis a todas as mulheres que englobem as diferentes modalidades nas quais a violência se expressa). 


\section{O Poder Judiciário e a atuação na questão da violência contra a mulher}

Consonante aos marcos sociais e as legislações, o Poder Judiciário também apresentou contribuições no que tange a iniciativas contra as situações de violência contra a mulher.

O Conselho Nacional da Justiça ${ }^{3}$, por exemplo, publicou em 2007 a Recomendação $n^{\circ} 9$ que indica aos Tribunais de Justiça a criação dos Juizados de Violência Doméstica e Familiar contra a mulher e a adoção de outras medidas que visem garantir os direitos humanos das mulheres no âmbito das relações domésticas e familiares. $\mathrm{Na}$ sequência, o mesmo órgão publicou o Manual de Rotinas e Estruturação dos Juizados de Violência Doméstica e Familiar contra a Mulher que padroniza os procedimentos e prevê a estruturação física e humana mínima para o seu adequado funcionamento - o que, gradativamente, vem sendo implantado nacionalmente.

Dentre a estrutura humana prevista, a legislação preconiza a constituição de equipes multidisciplinares, que se mostram como importantes instrumentos de efetivação da Lei através dos estudos, laudos e atendimentos prestados junto da população jurisdicionada, bem como de humanização do atendimento à vítima, cabendo-lhes:

[...] entre outras atribuições que lhe forem reservadas pela legislação local, fornecer subsídios por escrito ao juiz, ao Ministério Público e à Defensoria Pública, mediante laudos ou verbalmente em audiência, e desenvolver trabalhos de orientação, encaminhamento, prevenção e outras medidas, voltados para a ofendida, o agressor e os familiares, com especial atenção às crianças e aos adolescentes (BRASIL, 2006) [grifo nosso].

Desse modo, de acordo com as demandas identificadas e a peculiaridade das situações atendidas em cada Vara, cabe ao setor multidisciplinar não apenas vislumbrar iniciativas que contribuam para a análise e visibilidade social da questão da violência contra a mulher, mas também construir práticas condizentes com as necessidades das vítimas e familiares na ótica da sua proteção e efetivação da Lei, de forma

\footnotetext{
${ }^{3}$ Instituição pública que visa aperfeiçoar o trabalho do sistema judiciário brasileiro, principalmente no que diz respeito ao controle e à transparência administrativa e processual.
}

intra e extrainstitucional conforme a realidade em que se atua.

O Manual de Rotinas e Estruturação dos Juizados de Violência Doméstica e Familiar contra a Mulher prevê ainda que as equipes multidisciplinares também devem desenvolver ações articuladas de cunho preventivo junto à sociedade (ou seja, não limitar a atuação com a população jurisdicionada), ao citar como suas atribuições:

- Participar de reuniões internas e externas, conhecer, além de contribuir para a articulação, a mobilização e o fortalecimento da rede de serviços de atenção às famílias em situação de violência doméstica (Enunciado 16 do FONAVID);

- Realizar palestras para o público em geral, objetivando divulgação, esclarecimento e promoção do Juizado de Violência Doméstica e Familiar Contra a Mulher;

- Realizar capacitações com os integrantes da Rede Pública Municipal e Estadual (Saúde, Educação e Ação Social), Conselhos Tutelares, Conselhos Comunitários de Segurança Pública e demais órgãos afins visando ao aperfeiçoamento das ações de enfrentamento da violência doméstica e familiar contra a mulher.

- Captar recursos comunitários objetivando o fortalecimento da rede de apoio à mulher vítima de violência doméstica e familiar (BRASIL, 2010, p. 44).

Assim, pela característica da atuação e, no contexto das varas especializadas de atendimento à mulher em situação de violência, as equipes multidisciplinares têm grande relevância no processo de reconhecimento da realidade e de construção de práticas condizentes com a realidade local e as necessidades da população atendida.

\section{O Juizado de Violência contra a Mulher de Ponta Grossa}

O Juizado de Violência Doméstica e Familiar Contra a Mulher, Vara de Crimes contra Crianças, Adolescentes e Idosos e de Execução de Penas e Medidas Alternativas de Ponta Grossa é uma das seis Varas Especializadas do Estado do Paraná com competência para julgar crimes de violência contra a mulher. Teve sua instalação realizada em 27/11/2012 através da Portaria $n^{\circ}$ 
4.611/2012 do Tribunal de Justiça do Estado do Paraná com suas competências fixadas através da Resolução $n^{\circ} 70$ de 2012 do mesmo órgão, incluindo nelas a análise de situações de violência contra a mulher.

Além dos juízes titular e substituto e dos respectivos profissionais de assessoria aos magistrados, a equipe do Juizado é composta por técnicos e analistas judiciários com formação em Direito, bem como por uma assistente social e estagiários acadêmicos de Direito e de Serviço Social. As atividades desenvolvidas pelos referidos profissionais são distintas e separadas entre dois setores: o cartório e o setor de serviço social (assim denominado por, no momento, contar apenas com profissional dessa área).

Em suma, ao cartório há a incumbência da movimentação dos processos físicos e eletrônicos em trâmite no Juizado com o encaminhamento dos feitos conforme as determinações judiciais. Já ao setor de serviço social cabe, além da realização de laudos sociais que subsidiam a decisão dos magistrados, o atendimento especializado preconizado no artigo 29 da Lei Maria da Penha, tal como define Souza (2013, p. 204-205):

A chamada equipe multidisciplinar tem como incumbência principal a humanização do ambiente judiciário onde se desenvolve a atividade jurisdicional de atendimento aos casos onde a vítima é uma mulher que sofreu agressão no âmbito doméstico e familiar, de forma a permitir um atendimento mais completo e voltado para o respeito à dignidade de todos os envolvidos, com ênfase na pessoa vitimada e nos seus dependentes.

A legislação e as recomendações não pontuam práticas estanques quanto ao atendimento psicossocial da vítima e de seus dependentes, mas direciona a utilização dos instrumentais técnicos da equipe multidisciplinar para o seu atendimento e encaminhamento numa perspectiva de totalidade, nos quais aqueles são estimulados na sua capacidade de resiliência (superação das situações vivenciadas), bem como a encontrar alternativas de empoderamento e autonomia.

\section{Perfil das vítimas e mapa da violência}

A recente instalação do Juizado de Violência contra a Mulher da comarca de Ponta Grossa implicou a necessidade do reconhecimento das demandas institucionais para que o trabalho desenvolvido fosse conduzido de acordo com os interesses da população usuária, de forma que a atuação do referido Juízo não se limitasse à matéria do Direito Penal, mas contribuísse efetivamente para a proteção das vítimas numa perspectiva mais ampla e social.

Neste sentido, o setor de serviço social organizou a construção do perfil das vítimas e dos agressores atendidos pelo Juizado no ano de 2014, bem como o mapeamento das ocorrências de violência do mesmo período para a melhor compreensão do fenômeno, visando ampliar a atuação da equipe, inclusive através da articulação e o encaminhamento para a Rede de Enfrentamento à Violência contra a Mulher da cidade ${ }^{4}$ quando necessário.

Assim, o referido perfil foi construído através de estudo documental com a metodologia de pesquisa por amostragem (amostra por conglomerados), tendo sido foco da análise 286 processos eletrônicos de medidas protetivas de urgência ${ }^{5}$, incluindo os arquivados. O levanta-

\begin{abstract}
${ }^{4} \mathrm{O}$ conceito de rede de enfrentamento à violência contra as mulheres diz respeito à atuação articulada entre as instituições/ serviços governamentais, não-governamentais e a comunidade, visando ao desenvolvimento de estratégias efetivas de prevenção e de políticas que garantam o empoderamento e construção da autonomia das mulheres, os seus direitos humanos, a responsabilização dos agressores e a assistência qualificada às mulheres em situação de violência. [...] a rede de enfrentamento é composta por: agentes governamentais e não-governamentais formuladores, fiscalizadores e executores de políticas voltadas para as mulheres (organismos de políticas para as mulheres, ONG's feministas, movimento de mulheres, conselhos dos direitos das muIheres, outros conselhos de controle social; núcleos de enfrentamento ao tráfico de mulheres, etc.); serviços/programas voltados para a responsabilização dos agressores; universidades; órgãos federais, estaduais e municipais responsáveis pela garantia de direitos (habitação, educação, trabalho, seguridade social, cultura) e serviços especializados e não-especializados de atendimento às mulheres em situação de violência (BRASIL, 2011, p. 12-13).
\end{abstract}

\footnotetext{
${ }^{5} \mathrm{Em}$ todos os casos de violência doméstica e familiar contra a mulher, feito o registro da ocorrência, deverá a autoridade policial adotar, de imediato, os seguintes procedimentos, sem prejuízo daqueles previstos no Código de Processo Penal [...] remeter, no prazo de 48 (quarenta e oito) horas, expediente apartado ao juiz com o pedido da ofendida, para a concessão de medidas protetivas de urgência [...] Constatada a prática de violência doméstica e familiar contra a mulher, nos termos da Lei, o juiz poderá aplicar, de imediato, ao agressor, em conjunto ou separadamente, as seguintes medidas protetivas de urgência, entre outras:

I - suspensão da posse ou restrição do porte de armas;

II - afastamento do lar, domicílio ou local de convivência com a ofendida;

III - proibição de determinadas condutas, entre as quais: a) aproximação da ofendida, de seus familiares e das testemunhas, fixan-
} 
mento de dados foi lançado numa planilha considerando informações básicas e fundamentais para a caracterização do perfil das vítimas, cuja tabulação permitiu a construção de gráficos.

Os dados colhidos corresponderam a faixa etária, estado civil e número de filhos da vítima; informações do agressor como o sexo e grau de parentesco com a vítima; além de informações sobre o crime identificado nos autos, tais como: o tipo de violência sofrida pela vítima, a reincidência ou não das agressões, se houve pedido anterior de medidas protetivas de urgência ou desistência da referida medida no processo analisado. Ademais, também se coletou informações sobre a localização das ocorrências visando mapeá-las e identificar as regiões com maiores incidências na cidade de Ponta Grossa, dentre outros aspectos pertinentes.

Com as informações tabuladas, constatou-se que, quanto à faixa etária, há predominância da idade das vítimas entre 36 a 50 anos de idade (gráfico 1) e, quanto ao estado civil destas, nota-se que a maioria das vítimas são conviventes ou casadas (gráfico 2). Ademais, averiguou-se se tratarem de mulheres adultas, com relacionamentos estabelecidos e, como se pode observar no gráfico 3 , a maioria possui ao menos um filho.

\section{GRÁFICO 1: IDADE DA VITIMA.}

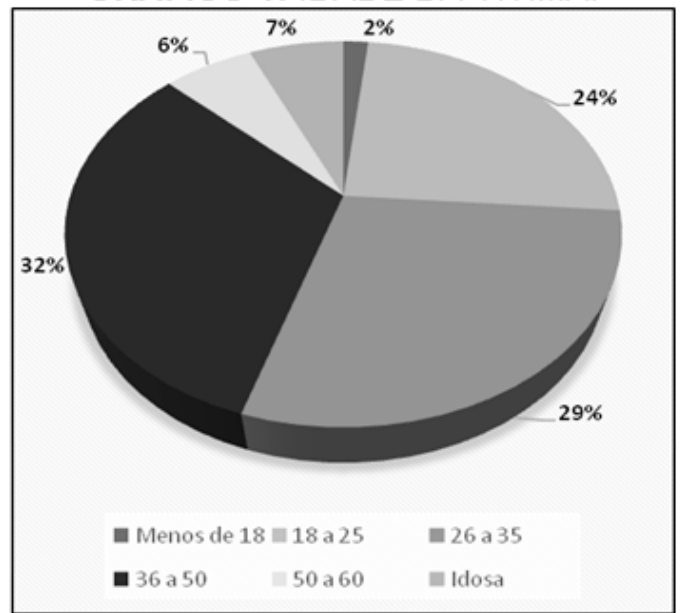

Fonte: Dados organizados pelas autoras

do o limite mínimo de distância entre estes e o agressor; b) contato com a ofendida, seus familiares e testemunhas por qualquer meio de comunicação; c) frequentação de determinados lugares a fim de preservar a integridade física e psicológica da ofendida; IV - restrição ou suspensão de visitas aos dependentes menores, ouvida a equipe de atendimento multidisciplinar ou serviço similar; e

V - prestação de alimentos provisionais ou provisórios (BRASIL, 2006).
GRÁFICO 2: ESTADO CIVIL DA VÍTIMA.

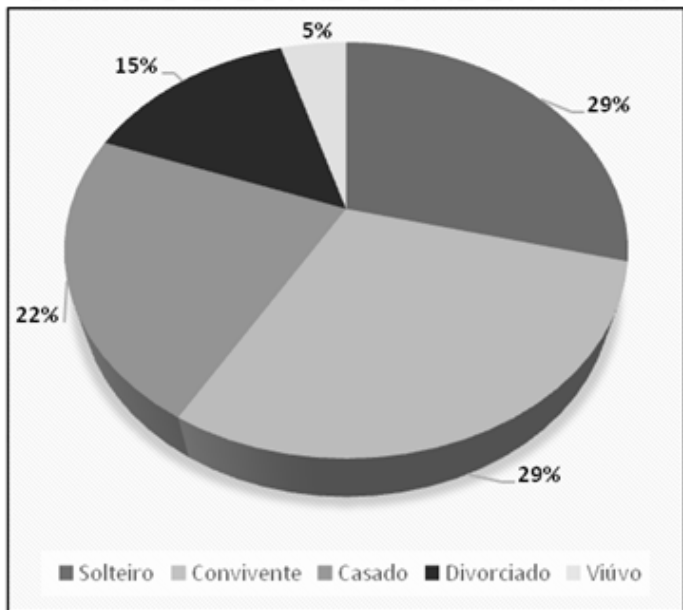

Fonte: Dados organizados pelas autoras

GRÁFICO 3: NÚMERO DE FILHOS DA VÍTIMA

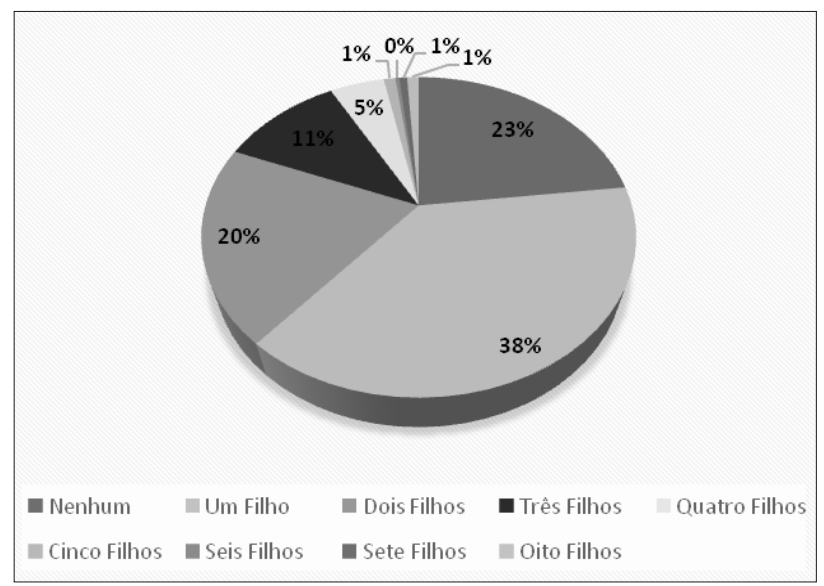

Fonte: Dados organizados pelas autoras.

Com base nos resultados deste tópico, nota-se que, na maioria dos contextos familiares analisados, há a presença de crianças ou adolescentes. Esse fato abre espaço para uma reflexão acerca das condições biopsicossociais de crianças e adolescentes que presenciam algum tipo de violência - aspecto sobre o qual pode-se compreender que,

As crianças que vivem em ambientes estressantes como os que têm violência doméstica são afetadas em sua capacidade de discriminação, tendo dificuldades para identificar o que é certo e o que é errado. Por exemplo, acham que o comportamento violento dos pais é normal, que todas as pessoas se relacionam dessa forma, que brigar e se agredir é comum, pois como o ser humano aprende por meio de modelos, este tipo de relação 
pode ser o único modelo pelo qual a criança aprendeu tal comportamento (WILLIAMS; MALDONADO \& PADOVANI, 2008, p.38).

Entende-se, a partir do exposto, que a maioria das crianças e adolescentes que presenciam algum tipo de agressão entre os familiares também acaba por se tornar vítimas desse contexto - o que pode provocar prejuízo no seu pleno desenvolvimento, bem como no entendimento de valores e nas relações interpessoais.

Nesse sentido, a possibilidade da criança e/ou adolescente desenvolver ao longo do tempo quadro de depressão, irritabilidade, agressividade, ansiedade e outros distúrbios emocionais é bastante saliente, motivo pelo qual considera-se que as intervenções profissionais, na medida do possível, também devam ser a elas estendidas.
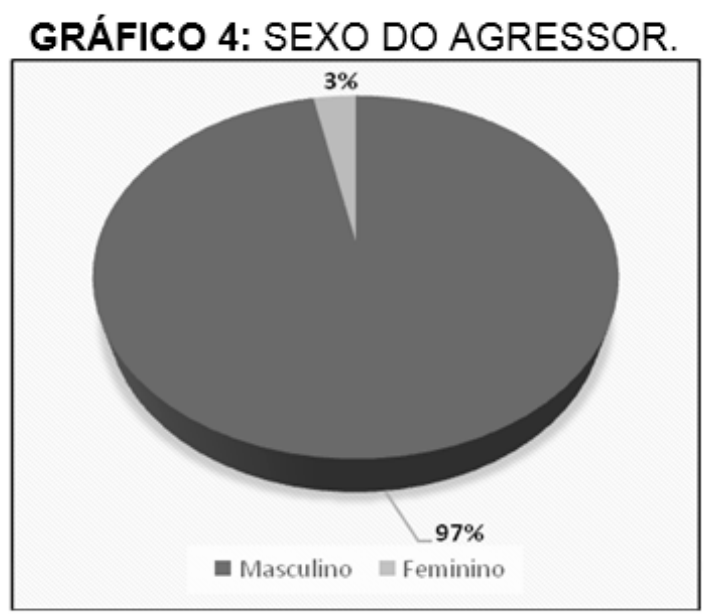

Fonte: Dados organizados pelas autoras.

\section{GRÁFICO 5: PARENTESCO ENTRE} VÍTIMA E AGRESSOR.

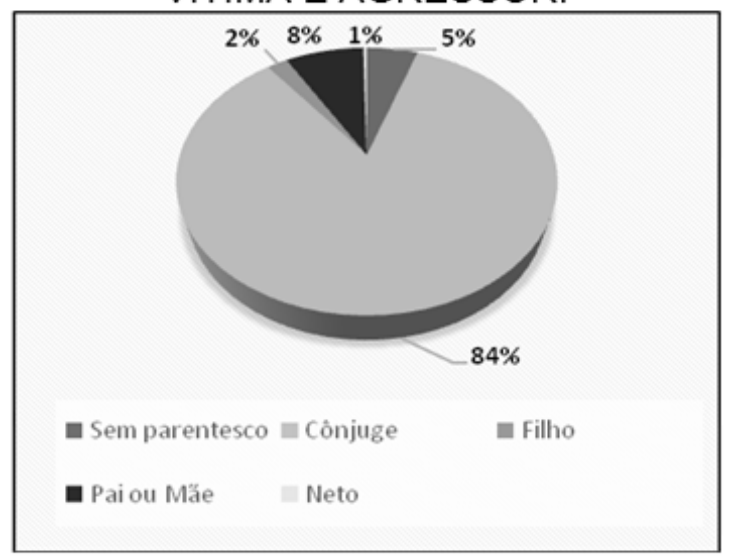

Fonte: Dados organizados pelas autoras.
Em continuidade à análise, constata-se nos dados acima a predominância dos agressores com sexo masculino (gráfico 4). Ademais, como se vê no gráfico 5 , tais agressores são em quase $90 \%$ das vezes o cônjuge - o que retrata que a realidade de muitas mulheres é conviver cotidianamente com a violência dentro de sua casa.

Através dos atendimentos prestados pelo setor de serviço social às vítimas, situações como a dependência química ou etílica, bem como comportamentos machistas por parte dos companheiros são por elas apontados como fatores motivadores das situações de violência. Tais informações além de outras possíveis motivações (embora não apuradas no presente levantamento por se tratarem de questões subjetivas), certamente merecem ser consideradas para se vislumbrar formas de intervenção junto às mulheres em situação de violência.

\section{GRÁFICO 6: TIPO DE VIOLÊNCIA SOFRI- DA PELA VÍTIMA.}

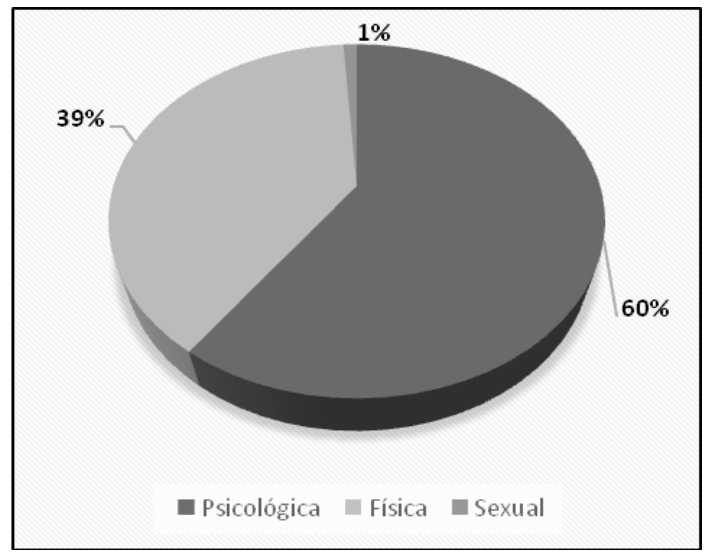

Fonte: Dados organizados pelas autoras.

A respeito dos tipos de violência, o levantamento de dados levou a constatação da predominância da violência psicológica, seguida da violência física, conforme sugere o gráfico acima. Nessa informação também pode-se conjeturar o machismo ainda fortemente influente em nossa sociedade. Neste contexto (construído social e culturalmente ao longo dos anos) o homem tende a mostrar superioridade através da imposição de valores ou do uso da força física, mesmo, em muitas vezes, tendo o entendimento dos malefícios que a violência física pode causar a mulher. 
Os prejuízos a saúde causados pela violência à mulher, tanto física como psicológica, podem ser inúmeros, entre eles, "[...] alterações de sono, problemas na alimentação, isolamento, medo, baixa autoestima, alto nível de ansiedade e depressão, ideação suicida, tentativas de suicídio, abuso de álcool e drogas e o uso não controlado de remédios" (WILLIAMS; MALDONADO; PADOVANI, 2008, p.24). E tais consequências certamente devem ser observadas pelos profissionais para a adequada abordagem e encaminhamento das mulheres em situação de violência.

Ainda a respeito da violência sofrida pelas mulheres atendidas no Juizado de Violência contra a Mulher de Ponta Grossa, obteve-se:

\section{GRÁFICO 7: VÍTIMA SOFREU VIOLÊN- CIAS ANTERIORES A REGISTRADA E QUE DEU INÍCIO AO PROCESSO?}

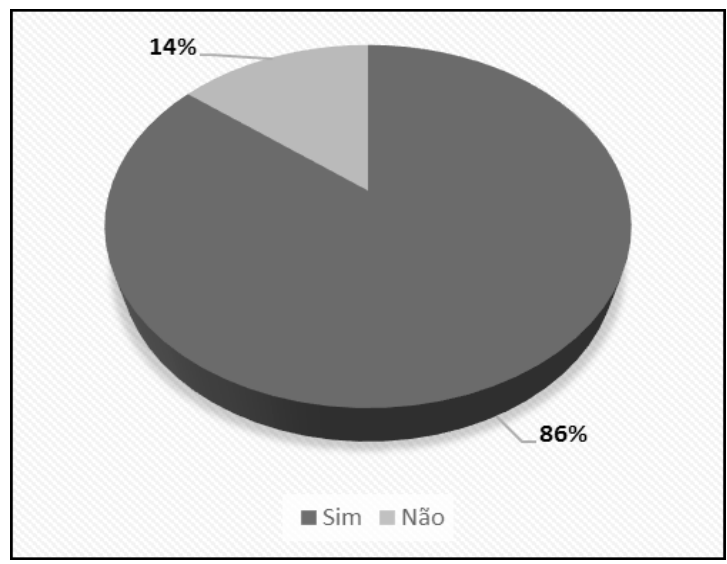

Fonte: Dados organizados pelas autoras.

\section{GRÁFICO 8: VÍTIMA JÁ HAVIA REQUERI- DO MEDIDAS PROTETIVAS ANTES?}

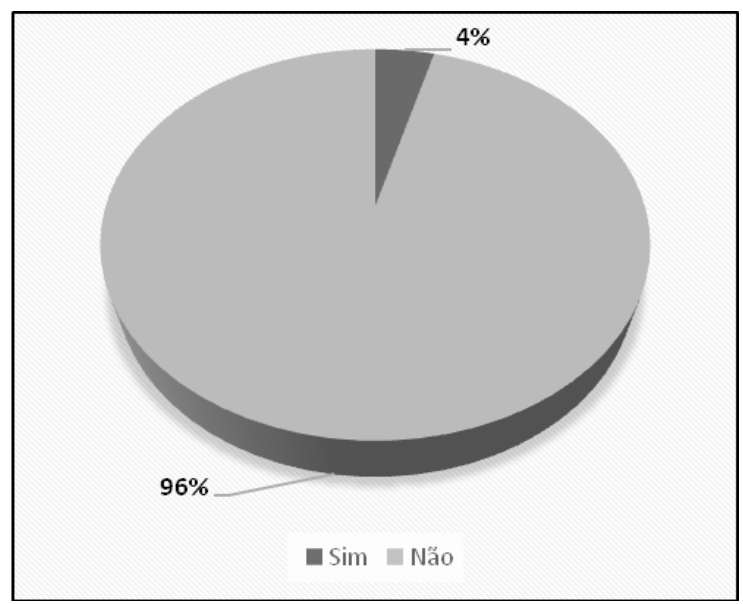

Fonte: Dados organizados pelas autoras.
Realizando uma análise sobre os dois gráficos acima, percebe-se o quão contraditório eles se mostram: enquanto gráfico 7 demonstra que a maioria das mulheres já havia sido vítima de violência em outras ocasiões anteriores ao processo levantado, o gráfico 8 expõe que a minoria delas não havia requerido medida protetiva de urgência, ou seja, o afastamento do agressor. Isso significa que a maior parte das vítimas de violência, por razões que também merecem ser investigadas, posterga as providências necessárias para a sua proteção, aguardando que a violência reincida para então vislumbrarem medidas contra o agressor.

Com base nos atendimentos realizados pelo setor de serviço social, constata-se que, geralmente, a maior motivação para que as vítimas não se distanciem de seus agressores é o vínculo afetivo (que permanece, mesmo depois da violência), a dependência financeira, ou ainda, a manutenção da proximidade dos filhos com a figura paterna e agressora. Esse dado, assim como os demais, também pode sugerir a forte presença do machismo na sociedade e nas famílias.

Não obstante, a literatura também apresenta elementos que subsidiam o exposto. Para Arraes (2015, p. 01), por exemplo:

Além do fator psicológico, muitas mulheres não possuem alternativas concretas e nem conseguem receber auxílio para deixarem o contexto em que sofrem agressões. Desde a falta de suporte da família, até a falta de recursos financeiros, muitos elementos se juntam e criam um verdadeiro muro de isolamento. [...] Em incontáveis casos, permanecer na relação sofrendo violência é a única alternativa para que aquela mulher continue comendo, vestindo e morando sob um teto - ainda que tudo isso seja controlado com crueldade.

Para aquela mulher que tem filhos com o agressor, a situação é ainda mais difícil [...]. Muitos abusadores usam os filhos como brecha para se aproximarem da vítima e muitas vezes essa única oportunidade acaba com a morte da mulher e até mesmo das crianças. 
GRÁFICO 9: VÍTIMA DESISTIU DE MEDIDA PROTETIVA NO PROCESSO ATUAL?

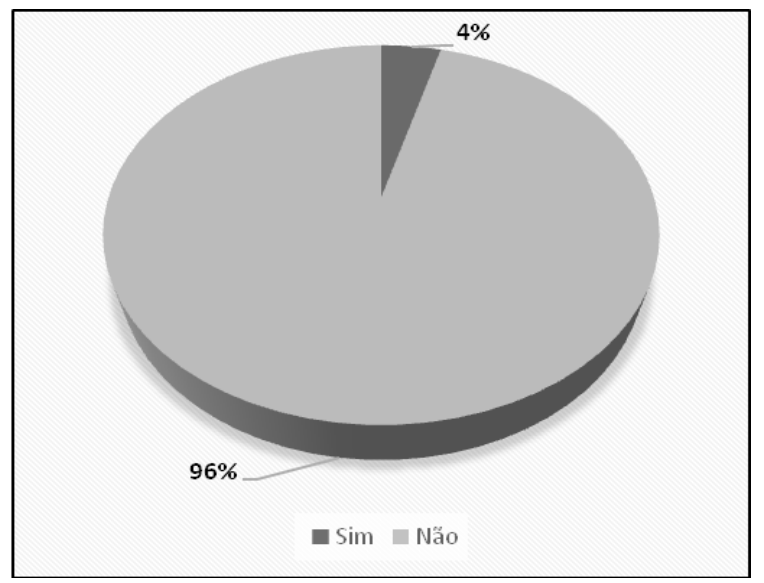

Fonte: Dados organizados pelas autoras.

Os dados obtidos com a construção do gráfico 9 mostram que não alcança $5 \%$ o número de processos em que ocorre a desistência da medida protetiva de urgência. Ou seja, esses dados apresentam-se de maneira positiva, pois, mesmo que postergada a decisão da mulher em situação de violência pelas medidas de proteção, a maioria delas não regride na sua decisão (ao menos nos autos de requerimento de medidas protetivas de urgência que ocorre anteriormente ao processo de representação criminal no qual a vítima pode desistir da representação e consequentemente das medidas protetivas) significando assim que a menor parte das vítimas retoma a convivência com o agressor.

Além das informações apresentadas, o presente estudo também tratou de levantar informações quanto ao local das ocorrências de violência contra a mulher, possibilitando o seu mapeamento (figura 1). Nesse sentido, não foram constatadas ocorrências nas regiões rurais da cidade, todavia, averiguou-se que elas ocorreram em todos os dezesseis bairros da cidade, com maior proporção no bairro de Uvaranas (46 ocorrências), seguido do bairro do Contorno (41 ocorrências), Oficinas (31), Boa Vista (24) e Neves (23), conforme pode ser visualizado na sequência.

\section{FIGURA 1: MAPEAMENTO DAS OCORRÊNCIAS DE VIOLÊNCIA NA CIDADE DE PON- TA GROSSA.}

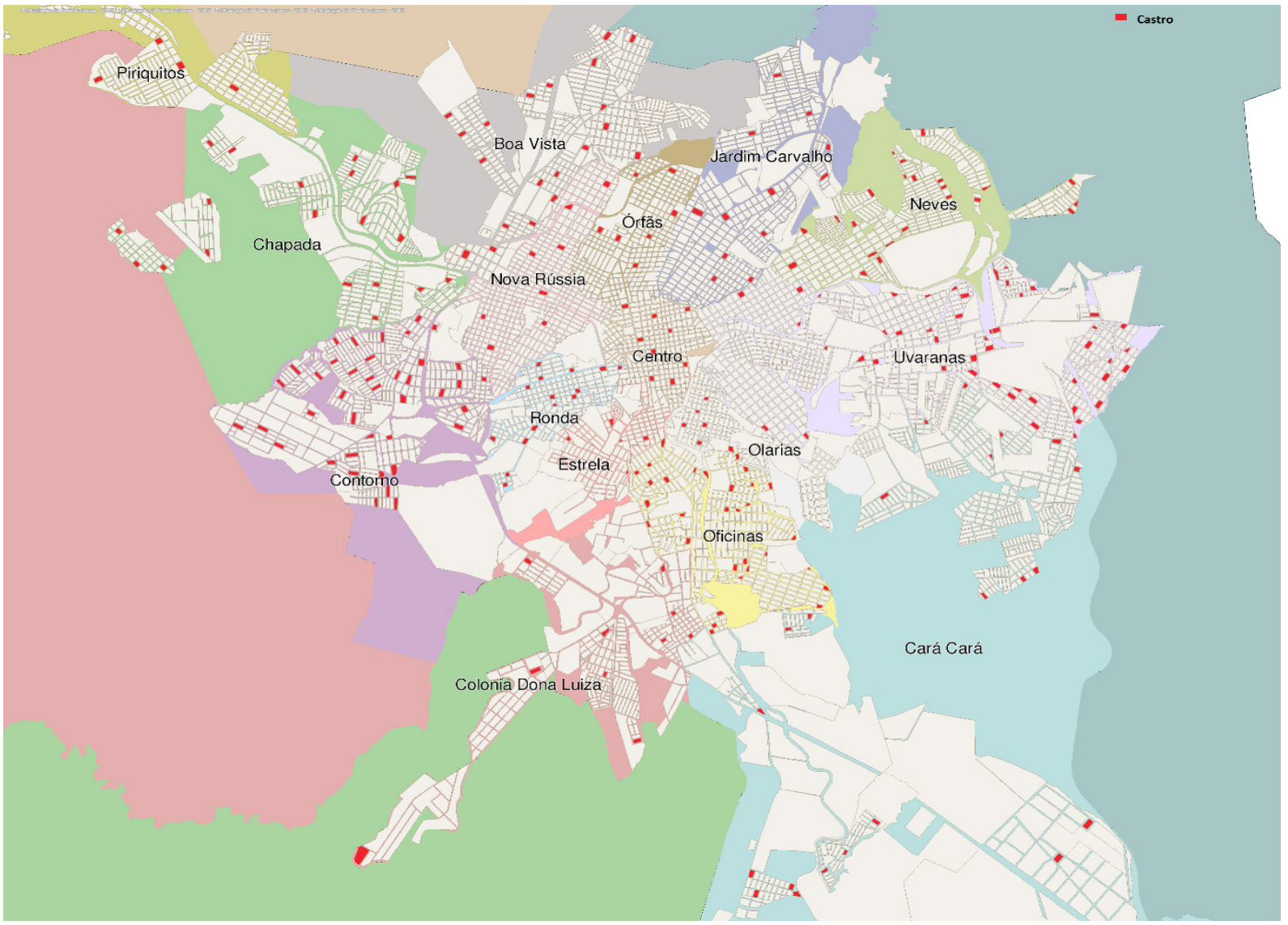

Fonte: Dados organizados pelas autoras. 
A distribuição das ocorrências, de modo geral, apresenta-se quase que de maneira uniforme, com exceção da região oeste de Uvaranas e norte de Olarias (mais próximas ao centro da cidade) onde as ocorrências foram praticamente nulas. Ademais, é possível verificar que há grande concentração de ocorrências nas regiões periféricas da cidade, especialmente à margem das principais rodovias que cortam a cidade, quais sejam: a BR-376 a oeste de Ponta Grossa (Avenidas Presidente Kennedy e Souza Naves em perímetro urbano); a PR-151 ao norte; e o Contorno Leste do município (Ruas Rio Cavernoso e Valério Ronchi, em Uvaranas).

A descentralização das ocorrências de violência contra a mulher na cidade de Ponta Grossa salienta uma grande limitação do Poder Judiciário: o fato de o espaço físico da instituição se situar em região central do município, provavelmente dificulta o acesso e o conhecimento do trabalho desenvolvido pelas mulheres que residem nas zonas periféricas da cidade, o que demonstra a importância da articulação com os equipamentos da Rede de Enfrentamento à Violência contra a Mulher que, de forma geral, estão situados em todas as regiões do município.

\section{Considerações Finais}

Estudos e dados recentemente divulgados evidenciam cada vez mais casos de violência contra a mulher. Tal realidade tem repercutido na ampliação dos espaços de discussão e na implantação de recomendações, políticas e práticas voltadas à superação da problemática.

Acompanhando esse movimento, o Juizado de Violência contra a Mulher da comarca de Ponta Grossa abarcou o propósito de construir práticas que superem a atuação pontual na questão e auxiliem na efetiva proteção da vítima. Assim, partindo do diagnóstico institucional, algumas reflexões emanaram, merecendo maior análise e aprofundamento no momento da construção de práticas condizentes com as demandas e necessidades da população atendida, tais como:

a) A presença de crianças e adolescentes nos contextos familiares em que a mulher é vítima de violência: uma vez que estudos comprovam que a coabitação em ambientes de violência traz consequências negativas às crianças e adolescentes, o acolhimento de suas demandas trata-se de algo bastante relevante na realidade do Juizado de Violência contra a Mulher, especialmente ao se preconizar a primazia do seu interesse e a sua proteção, garantidos em lei;

b) As alterações biopsicossociais nas muIheres vítimas de violência: reconhecer tais alterações e consequências da violência é essencial para a abordagem da sua realidade numa perspectiva de totalidade para a sua efetiva proteção. Neste contexto, encaminhamentos podem ser necessários, motivo pelo qual a identificação dos equipamentos e do funcionamento da Rede de Enfrentamento à Violência contra a Mulher no município também se apresenta como de grande relevância;

c) A predominância de agressores do sexo masculino, assim como a constatação da violência psicológica com maior índice de incidência: ambas podendo sugerir a forte presença do machismo na relação entre agressor e vítima - o que se trata de temática bastante relevante de ser abordada junto às partes, se comprovada a hipótese;

d) A motivação para as mulheres postergarem o pedido de medidas protetivas, mesmo sofrendo com situações de violência recorrentes, conforme apontam os dados: a análise concreta dessa informação pode auxiliar na identificação de formas de abordagem profissional que contribuam para a maior reflexão e empoderamento da vítima, tomando-se por base as hipóteses formuladas pelo setor de serviço social com base nos atendimentos realizados;

e) A constatação de que nos autos de medidas protetivas de urgência há mínima desistência das medidas - o que incita questionamentos: a vítima mantém seu posicionamento quando chamada a se manifestar quanto à representação criminal contra o agressor (processo posterior ao de medidas protetivas)? Qual seria a incidência de desistência das medidas protetivas de urgência nos procedimentos para a representação criminal (que ocorrem, em média, um ano após o processo de medidas protetivas)? E quais seriam os fatores motivadores da sua decisão?

f) A importância do reconhecimento e articulação com a Rede de Enfrentamento à Violência contra a Mulher da cidade: não apenas para encaminhamentos, mas para acolhimento de demandas judiciais identificadas e conduzidas ao Poder Judiciário pelos diversos equipamentos 
(uma vez que, ao contrário do Juizado, tais instituições situam-se descentralizadas no município).

Por fim, inerente ao mapeamento das ocorrências de violência contra a mulher foi possível identificar que o número de casos na cidade de Ponta Grossa é bastante significativo e que ocorre em todas as áreas urbanas da cidade, especialmente nas regiões periféricas, com maior incidência em determinados bairros. Nesse contexto, também emergem alguns questionamentos: existem motivações específicas para a maior incidência nesses locais? Os equipamentos da Rede de Enfrentamento à Violência contra a Mulher estão presentes nesses espaços desenvolvendo ações preventivas e/ou protetivas?

Em suma, vê-se que as informações elencadas no presente estudo servem para iniciar a discussão sobre a questão da violência contra a mulher no município de Ponta Grossa, elucidando pontos que necessitam de maior atenção. Ademais, ponderando-se que é recente a instalação do Juizado de Violência contra a Mulher na referida comarca, os dados ora elencados se apresentam como diagnóstico institucional a partir do qual será possível a construção de projetos e intervenções específicas para esse perfil a serem implantadas.

\section{Referências}

ARRAES, Jarid. Por que elas continuam com seus agressores? In: Revista Fórum. Disponível em: http://www.revistaforum.com.br/ questaodegenero/2015/08/18/

por-que-elas-continuam-com-seus-agressores/. Acesso em: 17 jan. 2016.

BRASIL. Constituição (1988). Constituição da República Federativa do Brasil. Brasília, DF: Senado Federal: Centro Gráfico, 1988. 292 p.

BRASIL. Lei $n^{\circ}$ 11.340/2006. (Lei Maria da Penha). Cria mecanismos para coibir a violência doméstica e familiar contra a mulher e dá outras providências. Promulgada em 07 de agosto de 2006.

BRASIL. Manual de Rotinas e Estruturação dos Juizados de Violência Doméstica e Familiar contra a Mulher. Brasília: Conselho Nacional de Justiça, 2010.

BRASIL. Pacto Nacional pelo Enfrentamento à Violência contra a Mulher. Presidência da República/
Secretaria de Políticas para as Mulheres. Brasília: 2007.

BRASIL. Plano Nacional de Políticas para as Mulheres. Presidência da República/Secretaria Especial de Políticas para as Mulheres. Brasília: 2005.

BRASIL. Recomendação $n^{\circ}$ 09. Conselho Nacional de Justiça - CNJ. Recomenda aos Tribunais de Justiça a criação dos Juizados de Violência Doméstica e Familiar contra a Mulher e a adoção de outras medidas. Publicada em 08/03/2007.

BRASIL. Rede de Enfrentamento à Violência contra as Mulheres. Presidência da República/Secretaria de Políticas para as Mulheres. Brasília: Secretaria Nacional de Enfrentamento à Violência contra as Mulheres, 2011.

DIAS, Sandra Pereira Aparecida. Um breve histórico da violência contra a mulher. 2010. Disponível em: http://araretamaumamulher.blogs.sapo.pt/16871.html. Acesso em: 04 set. 2015.

IPEA. Violência contra a mulher: feminicídios no Brasil. Instituto de Pesquisa Econômica Aplicada, 2013. Disponível em: <http://www.ipea.gov.br/portal/ index. php? option=com_content\&id=19873>. Acesso em: 10 jun. 2015.

PARANÁ. Tribunal de Justiça do Estado do Paraná. Portaria $n^{\circ} 4.611 / 12$. Designa data para Instalação do Juizado de Violência Doméstica e Familiar Contra a Mulher, Vara de Crimes contra Crianças, Adolescentes e Idosos e de Execução de Penas e Medidas Alternativas da Comarca de Ponta Grossa. Publicada em 20/11/2012.

PARANÁ. Tribunal de Justiça do Estado do Paraná. Resolução $\mathbf{n}^{\circ} \mathbf{7 0 / 1 2}$. Fixa a competência dos Juizados Juizado de Violência Doméstica e Familiar Contra a Mulher, Vara de Crimes contra Crianças, Adolescentes e Idosos e de Execução de Penas e Medidas Alternativas. Publicada em 8 de outubro de 2012.

PEREIRA, Malila Natasha da Costa; PEREIRA, Maria Zuleide da Costa. A violência doméstica contra a mulher. In: Revista Espaço do Currículo, v. 4, $n^{\circ} 01$ : João Pessoa, 2011.

PINAFI, Tânia. Violência contra a Mulher: Políticas Públicas e medidas protetivas na contemporaneidade. In: Revista Histórica. Edição nº 21. São Paulo: Arquivo do Estado, 2007. Disponível em: http://www.historica. arquivoestado.sp.gov.br/materias/anteriores/edicao21/ materia03/. Acesso em: 04 set. 2015. 
SOUZA, Sérgio Ricardo de. Lei Maria da Penha comentada sob a nova perspectiva dos direitos humanos. $4^{\mathrm{a}}$ edição revista e atualizada. Curitiba: Juruá Editora, 2013.

WAISELFISZ, Julio Jacobo. Mapa da Violência 2012: caderno complementar de homicídio de mulheres no Brasil. São Paulo: Instituto Sangari, 2012. Disponível em: http://www.mapadaviolencia.org.br/pdf2012/ mapa2012_mulher.pdf. Acesso em: 10 jun. 2015.

WILLIAMS, Lúcia Cavalcanti de Albuquerque; MALDONADO, Daniela Patrícia Ado; PADOVANI, Ricardo da Costa. Uma vida livre da violência. Cartilha, 2008. Universidade Federal de São Carlos - Departamento de Psicologia, São Carlos. Disponível em: <http://www.Ifcc.on.ca/uma_vida_livre_da_ violencia.pdf $>$. Acesso em: Jun/2015. 